\title{
Evaluation of Efficacies of Different Concentrations of Citrus Fruit Extracts against Indoor Adult Mosquitoes in Abini, Cross River State, Nigeria
}

\author{
Effiom O. E.,Ubi P. O.,Olushola T. O., Ibeh E. O.
}

\begin{abstract}
Aim: This study aimed to verify the mosquitocidal activity of phytochemical extracts from peels, pulp and seeds of citrus fruits species against adult mosquitoes in the field.

Materials and methods:The peels, pulp and seeds of Citrus sinensis, Citrus aurantifolia, Citrus limonum, Citrus reticulata and Citrus vitis were obtained and air-dried for 3 weeks, under axenic conditions. They were then ground into powder, and by Soxchlet extraction method using diethyl ether (as solvent), the volatile phytochemical extract was obtained at temperature range of $600 \mathrm{C}-800 \mathrm{C}$ for 6 hours. The active compounds were characterized using appropriate standard methods for qualitative and quantitative. Five different concentration grades, $5 \%, 10 \%, 15 \%, 20 \%$ and $25 \%$, were then prepared volume for volume, from each extract stock. 75 human living rooms were randomly selected in a rural community of Abini, Biase LGA of Cross River State, and then exposed sufficiently for mosquitoes to enter. All food items, the floor, surfaces and undersurfaces of furniture were covered with white sheets, and all the doors and windows were shut, and using insecticide spray pumps, the rooms were then sprayed with the extracts in aerosol form (i.e., one concentration per room). 30minutes later the rooms were opened, and with the help of a bright torch light the, mosquitoes that had dropped dead on the white sheet were picked up using forceps, and counted. This spray exercise was repeated two weeks later with the same extracts but this time the concentrations were alternated with the rooms.
\end{abstract}

Results:ntrations of the extracts used produced reasonable mosquito death in the respective rooms they were sprayed except the 5\% that did not kill any mosquito. A correlation test to establish the relationship between the numbers of mosquitoes killed and the different concentrations proved significant $(P>$ 0.01). A similar test to verify the relationship between the species of citrus fruits and the corresponding numbers of the different mosquito species killed by their extract concentrations also proved significant $(P>0.01)$.

Conclusion: Therefore, phytochemical extracts, having shown sufficient potency against adult mosquitoes, suggest that they could be successfully adopted in sustainable control of malaria vectors.

Index Terms-Mosquitocidal Activity, Citrus Fruit Extracts, Malaria Vectors.

\section{INTRODUCTION}

The mosquito group (Diptera: Culicidae) is the major group of insects that cannot be very easily ignored in medical

Effiom O. E., Department of Biotechnology and Environmental Biology, Veritas University, Abuja, FCT., Nigeria.

Ubi P. O., Department of Biotechnology and Environmental Biology, Veritas University, Abuja, FCT., Nigeria.

Olushola T. O., Department of Biotechnology and Environmental Biology, Veritas University, Abuja, FCT., Nigeria.

Ibeh E. O., Department of Biotechnology and Environmental Biology, Veritas University, Abuja, FCT., Nigeria. entomological studies because they serve as vectors and transmitters of many tropical and subtropical diseases of public health importance $(25,2)$. It is also true that mosquito-borne diseases such as malaria, lymphatic filariasis, dengue, yellow fever, etc., have contributed immensely to the prevailing most worrisome high human disease burden and high mortality besides poverty, pestilence and social delibility in the tropics today (30).

Whereas earlier studies had reported that only about 60 species of mosquitoes of the genus Anopheles are proven to be involved in plasmodial transmission all over the world ( 8 , 14), recent reports have maintained that there are over 300 species of mosquitoes belonging to 39 genera and 135 subgenera which are incriminated in the transmission of the four Plasmodium species that cause malaria in man in the different parts of the world (31).

One of the most challenging public health issues of global concern is insect vector control, and that may probably be the reason why many approaches have been evolved and adopted at various levels to tackle the menace of insect vectors. Unfortunately, rather than keep these insect-borne diseases on proper check, plasmodial transmission is spreading farther and farther with maximum rapidity across international boundaries. This is evident by the annual high morbidity of about 300-500 million cases with a mortality of about 1-3million globally (5). Making the matter worst is the fact that mosquito control with synthetic organo-chemical insecticides (like DEET which had been in use over 50 years ago) has now lost its effectiveness perhaps following emergence of insecticide-resistant mosquito sibling species, toxic side effects on non-target ecosystem because of the non-biodegradability of the chemical compounds in addition to expensiveness (24). It is therefore this challenge that necessitated the desire for the development of natural plant-based alternative insecticides which besides being readily available and cheap, are also environmentally friendly and safe and biodegradable $(15,24,13,31)$.

The use of citrus fruits as source of phytochemicals in the sustainable control of insect vectors would help effectively to clear the unutilized bulk and heaps of citrus fruits dumped as waste in our indigenous markets and citrus plantations.

A review of literature on control of different species of mosquito showed that evaluation of different phytochemicals from various plants have been carried out by a number of researchers on vector control (15), but with very minimal assessment of insecticidal potentials of various species of citrus fruits. Plants such as, Ageratinaadenophora (Spreng) have been sufficiently exploited against mosquito species of Aedesaegypti and Culexquinquafasciatus (12). Ocimum 
sanctum Linn. has also shown larvicidal and repellent activity against $A$. aegypti, and Neem seed kernel extracts have been used too as larvicides against $A$. aegypti $(10,28)$. Similarly, a detailed laboratory study on extracts of fruits of Piper nigrum Linn. against larvae of Culexpipines, A. aegyptiand A. togoi have also been reported (29). This comparative work was undertaken to investigate and thus add to the knowledge of efficacy of citrus fruit species in sustainable control of Anopheles gambiae and Anophelesfunestus, the prevalent vectors of malaria in Cross River State, Nigeria.

\section{MATERIALS AND METHODS}

\section{Study Duration}

This six months study was conducted between April 2017 and September 2017, in Abini Village ofBiase LGA., Southern Senatorial District of Cross River State, Nigeria

\section{Sources of the citrus fruits and their identification into species}

Citrus fruits were obtained from the indigenous markets of Ika-IkaOqua, Mbukpa and Watt markets in Calabar, Cross River State, and the identification keys of Swingle and Reece (16), Hodgson(21), Wardowskiet al., (18), Morton (4), Cottin (9) and Koskinen (1) were used in identifying the citrus into species.

\section{Extracts preparation}

The fruits were first washed clean under tap water to remove sand and other possible contaminants. The epicarp was peeled off as thinly as possible unto clean white sheets of cardboard paper. The entire endocarp (all pulp) of each peeled fruit was removed and the juice in it was exhaustively expressed out, and the moist chaffs were spread on another set of white sheets of cardboard papers. The seeds too were removed, washed and spread similarly. The cardboard sheets carrying the peels, pulp and seeds were left on the laboratory benches for 21 days to air-dry. Maximum care was taken to avoid contamination from the laboratory environment. At the end of the three weeks the air-dried peels, pulp and seeds were ground into powdered materials using adequately sterilized Corona manual grinding machine and stored separately in air-tight glass bottles ready for phytochemical oil extraction. The volatile oils were exhaustively extracted from the materials by means of Soxchlet extractor using Diethyl Ether as solvent at temperature range of between $60^{\circ} \mathrm{C}$ and $80^{\circ} \mathrm{C}$ for 6 hours. The extracts were thereafter left overnight at laboratory temperature of $28.5^{\circ} \mathrm{C}$ for the remaining Ether in it to evaporate.

Determination of the active ingredients in the extracts

The active ingredients of the phytochemicals were determined using appropriate standard methods as described by Harborne (11) for alkaloids and phenolics, Van Burden and Robinson (17) for tannins, Obadoni and Ochuko (6) for saponins, and Boham and Kocipai (23) for flavonoids.

Preparation of the different concentrations of the extracts

Five different concentration grades, 5\%, 10\%, 15\%, 20\% and $25 \%$, were prepared from the peels, pulp and seeds extract stocks by volume for volume dilution, into correspondingly labeled insecticide-spray hand pumps.

Test of efficacy of the citrus extracts in the field against indoor adult mosquitoes

The insecticide spray sheet method of WHO (1992a) was adopted in this field demonstration using insecticide-spray hand pump.

Seventy five (75) randomly selected human living rooms in a malaria endemic community of Abini, Biase Local Government Area of Cross River State, Nigeria were first exposed sufficiently between the hours of 6.30 and $8.30 \mathrm{pm}$ to allow enough mosquitoes to enter. The insecticide spray method described by WHO (19) was then applied. A white sheet was then spread to cover the floor, other surfaces and undersurfaces of furniture, under-tables, under-beds and other places where mosquitoes may hide. This was carefully and neatly done to ensure that no sheet placed on furniture was allowed to hang down to the floor because such hanging of sheet of paper may prevent the spray from reaching the mosquitoes that may be hiding under the furniture. All doors and windows were then shut, and the concentrations were sprayed, one concentration per room, beginning from the outside of the room, all open spaces, holes on the walls, and the eaves. Still with the doors and windows closed, the inside of the room was sprayed with the same concentration of extract sprayed on the outside. The time of the inside spraying was noted. The rooms were opened 30minutes later and with the help of a bright torch light the mosquitoes that have dropped dead on the white sheet were picked up using forceps, and counted. This spray exercise was repeated two weeks later with the same extracts except that the concentrations were during the repeat spraying alternated with the rooms. The average number of mosquitoes killed by each concentration was computed and compiled. A period of two weeks was spent in the community to conduct this exercise.

Identification of the dead indoor adult mosquitoes

Using their morphometric parameters, the dead adult mosquitoes collected were identified into two genera, Culicines (i.e., Culex, Aedes) and Anophelines (i.e., Anopheles gambiae and funestus) to determine the genus most affected by the sprayed extracts (14). The result obtained was as shown in Table 1 below.

\section{Analysis of data}

The data obtained during this study were subjected to statistical analysis using the Chi-square test (of SPSS Model 15), to ascertain the significance of the observed variations in MLCs of the different phytochemical extracts compared, and with those of the control Altosid liquid larvicide.

\section{RESULTS}

An average of one thousand one hundred and seventy two (1172) adult mosquitoes was killed in the 75 living rooms that were sprayed with the different concentrations of the extracts in Abini (Biase). 


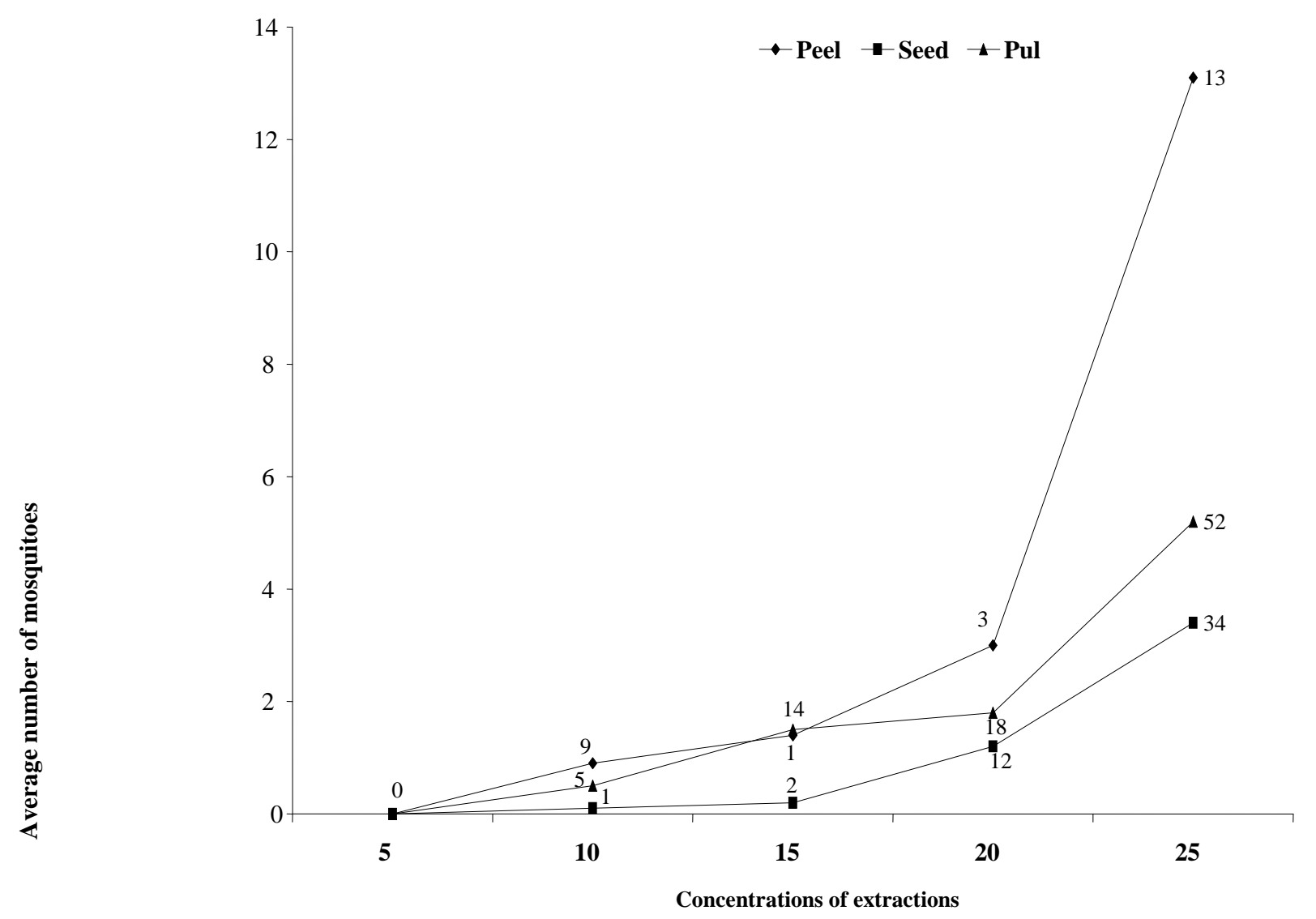

Fig. 1a: Adult mosquitoes killed by different concentrations of the different extracts from Citrus sinensis(Sweet orange) in Abini (Biase) Community, and with peel extract killing the highest number (131) at $25 \%$ concentration 
Evaluation of Efficacies of Different Concentrations of Citrus Fruit Extracts against Indoor Adult Mosquitoes in Abini, Cross River State, Nigeria

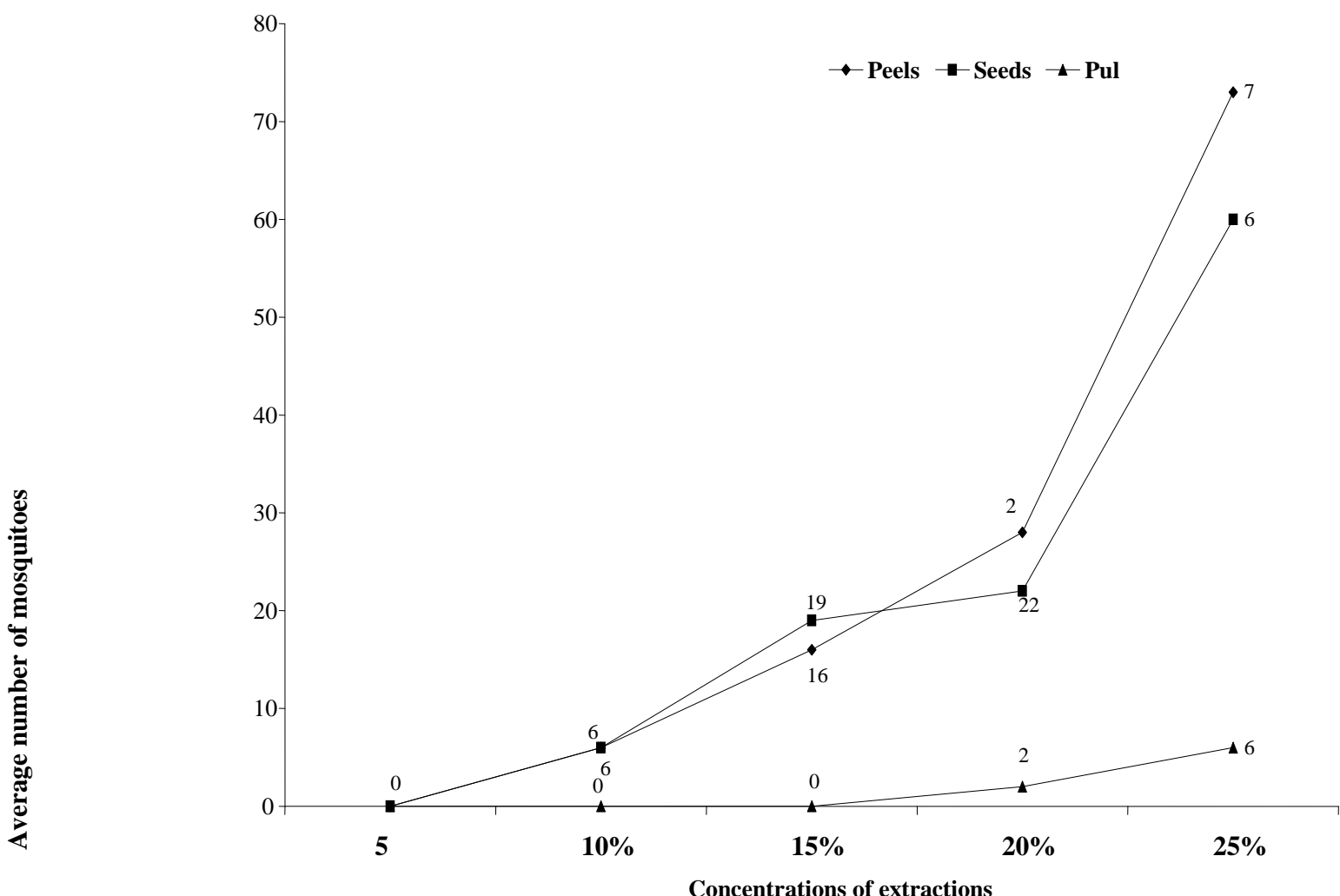

Fig. 1b: Adult mosquitoes killed by different concentrations of the different extracts from Citrus aurantifolia(Lime) in Abini (Biase) Community, and with peel and seed extracts competing with 73 and 60 mosquitoes, respectively at $25 \%$ concentration

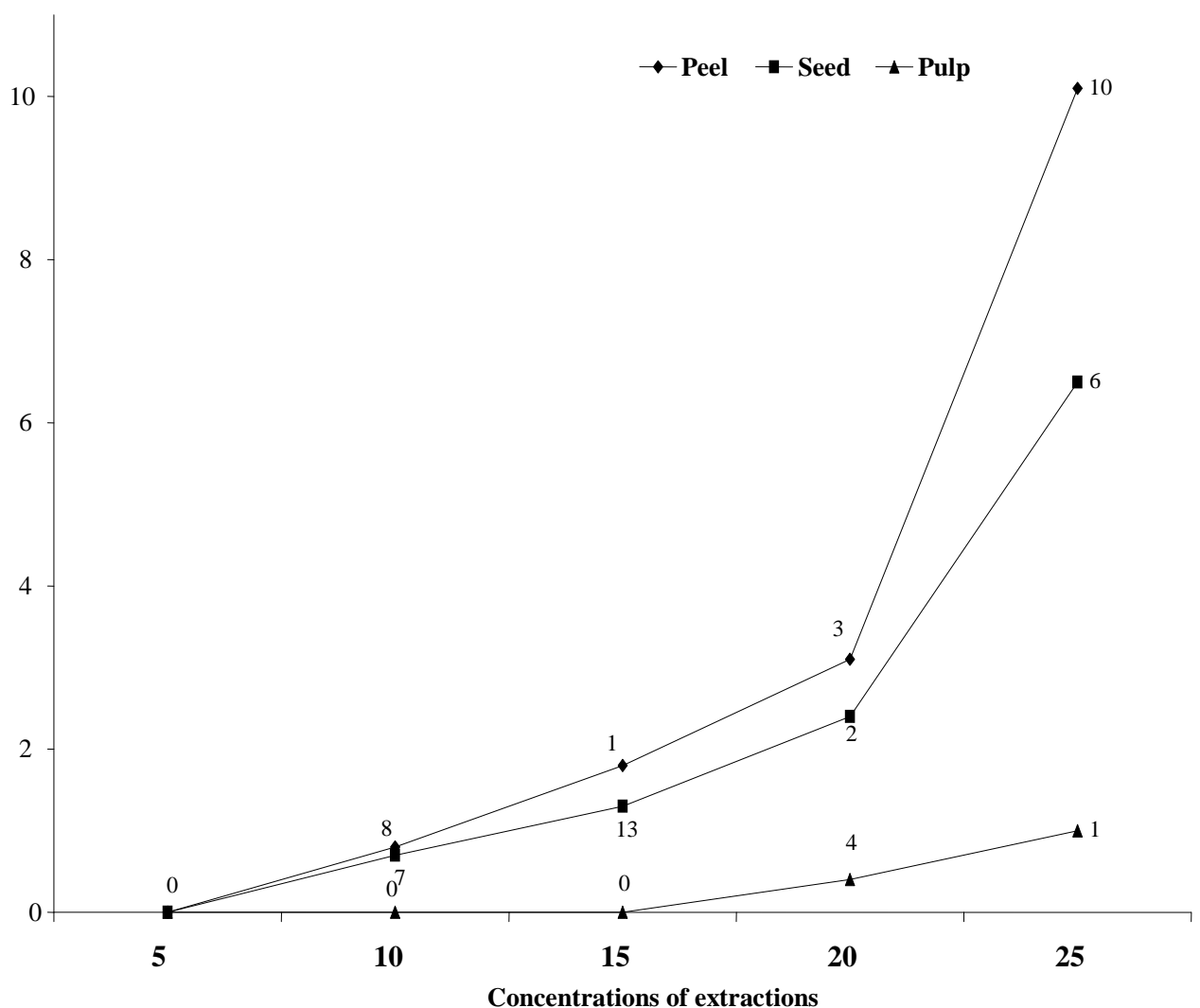

Fig. 1c: Adult mosquitoes killed by different concentrations of the different extracts from Citrus limonium (Lemon) in Abini (Biase) Community, and with peel extract killing the highest number (101) at $25 \%$ concentration 


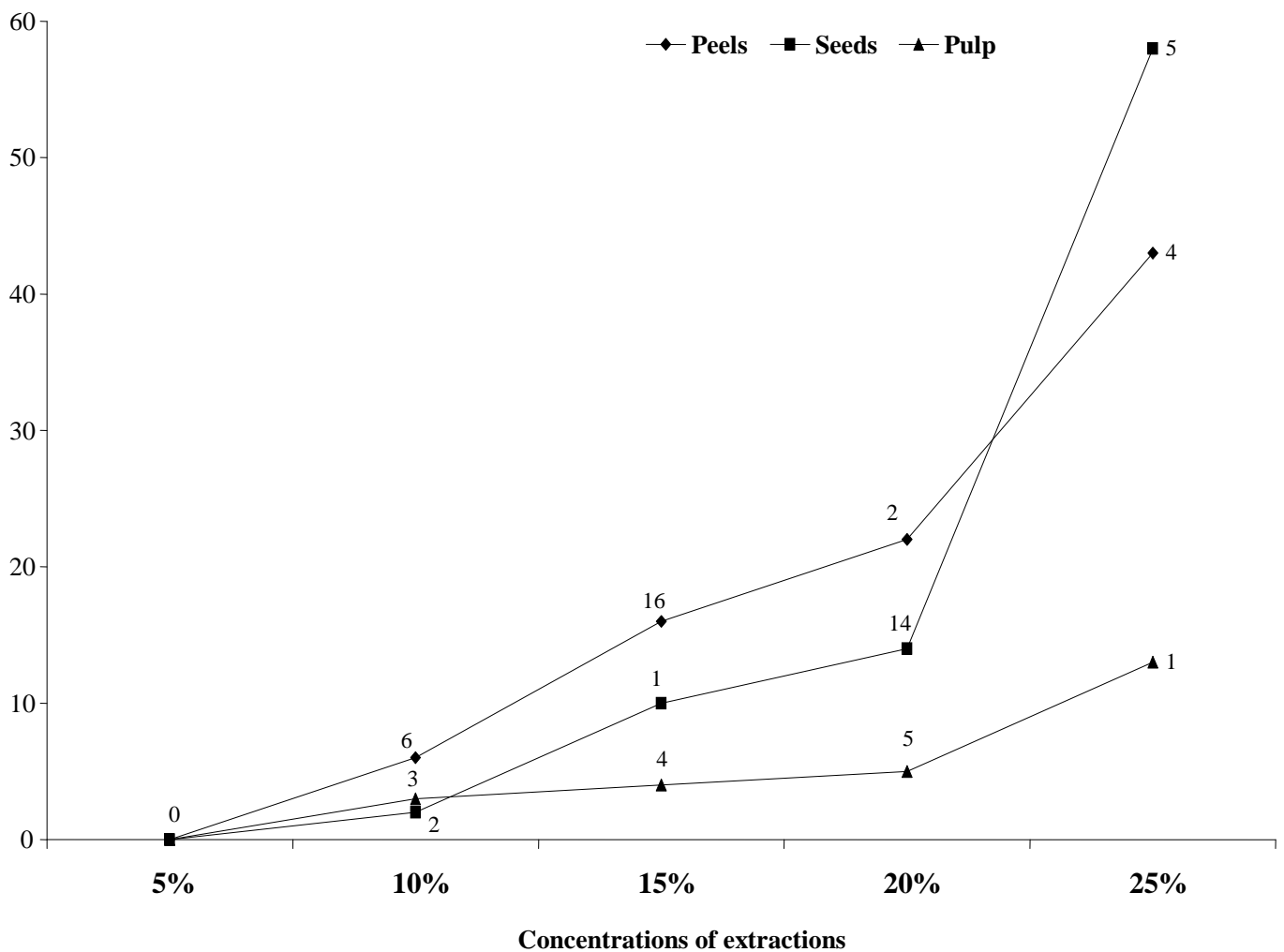

Fig. 1d: Adult mosquitoes killed by different concentrations of the different extracts from Citrus reticulata (Tangerine) in Abini (Biase) Community, and with seed extract killing the highest number (58) at $25 \%$ concentration

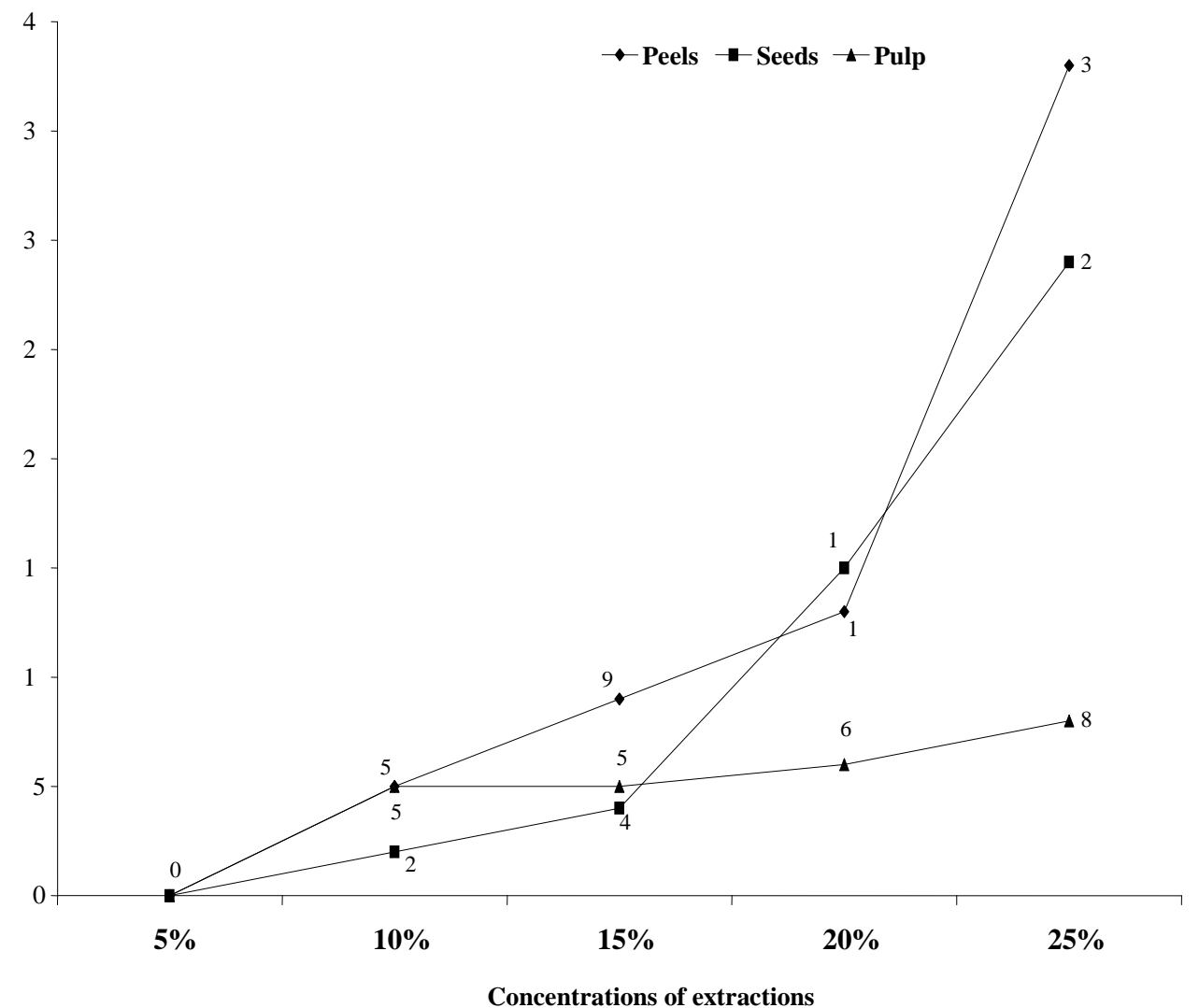

Fig. 1e: Adult mosquitoes killed by different concentrations of the different extracts from Citrus vitis (Grape) in Abini (Biase) Community, and with peel extract killing the highest number ( 38 ) at $25 \%$ concentration 


\section{Evaluation of Efficacies of Different Concentrations of Citrus Fruit Extracts against Indoor Adult Mosquitoes in Abini, Cross River State, Nigeria}

It was also observed that other arthropods such as houseflies, cockroaches and spiders were equally affected as a few dead ones were found in the rooms sprayed with higher concentrations of the extracts.

Table 1: Shows the distribution of identified dead indoor resting adult mosquitoes picked from the sprayed rooms

\begin{tabular}{|l|l|l|l|c|}
\hline Mosquito & \multicolumn{2}{|l|}{ Culicines } & \multicolumn{2}{|l|}{ Anophelines } \\
\hline Genus/Species & Culex & Aedes & Anopheles gambiae & Anopheles funestus \\
\hline Number & 182 & 142 & 532 & 296 \\
\hline Total & 324 & 848 & \\
\hline Grand Total & 1172 &
\end{tabular}

Of the 1172 dead indoor adult mosquitoes picked from the rooms sprayed, $324 / 28 \%$ were

identified as Culicines comprising 181/55.9\% Culex mosquitoes and 143/44.1\% Aedes

mosquitoes. The remaining 848/74\% were Anophelines of which 532/62.7\% were Anopheles

gambiae and 316/37.3\% were Anopheles funestus.

It was observed from qualitative analysis result that all volatile oil extracts from the peels and pulp of the five species of citrus fruits showed the presence of alkaloids whereas all the extracts from seeds except that of $C$. aurantifolia (lime) showed absence of alkaloids. Flavonoids were observed in the peel extracts of all the five citrus fruits and in the extracts from seeds of $C$. reticulata, $C$. aurantifolia, and $C$. vitis. The extracts from the pulp of all the five species of citrus fruits and the seeds of $C$. sinensis showed absence of flavonoids.

There were no Saponins in all the extracts from peels, seeds and pulp of three citrus species (C. sinensis, $C$. aurantifolia and C. vitis).

Only extracts from the pulp of two citrus species $(C$. reticulata and $C$. limonum) indicated the presence of Saponins. The extracts from peels, and seeds of $C$. sinensis, $C$. limonium and $C$. aurantifolia showed the presence of tannins, but the peels, pulp and seeds of $C$. reticulata and $C$.

vitis did not show tannins in their extracts. $\quad$ gave the values recorded in Table 2.
Table 2: The result of quantitative determination of the Chemical compounds (i.e. active ingredients) present in th phytochemical extracts from peels, pulp and seeds of the five species of citrus fruits.

\begin{tabular}{|c|c|c|c|c|}
\hline \multirow{2}{*}{$\begin{array}{l}\text { Chemicals } \\
\text { Compound } \\
\text { determined }\end{array}$} & \multirow[t]{2}{*}{ Species of Citrus fruit } & \multicolumn{3}{|c|}{ Source of volatile oil extract } \\
\hline & & Peels & Pulps & Seeds \\
\hline \multirow{5}{*}{$\begin{array}{l}\text { Alkaloids } \\
(\mathrm{mg} / \mathrm{l})\end{array}$} & C. sinensis(Sweet orange) & 0.005 & 0.005 & 0.000 \\
\hline & C. reticulata(Tangerine) & 0.010 & 0.010 & 0.000 \\
\hline & C. limonum(Lemon) & 0.010 & 0.015 & 0.000 \\
\hline & C.aurantifolia(Lime) & 0.005 & 0.005 & 0.010 \\
\hline & C.vitis(Grape fruits) & 0.010 & 0.005 & 0.000 \\
\hline \multirow{5}{*}{$\begin{array}{l}\text { Flavonoids } \\
(\mathrm{mg} / \mathrm{l})\end{array}$} & C. sinensis(Sweet orange) & 0.040 & 0.020 & 0.000 \\
\hline & C. reticulata(Tangerine) & 0.040 & 0.005 & 0.015 \\
\hline & C. limonum(Lemon) & 0.020 & 0.010 & 0.025 \\
\hline & C.aurantifolia(Lime) & 0.025 & 0.030 & 0.010 \\
\hline & C.vitis(Grape fruits) & 0.050 & 0.030 & 0.010 \\
\hline \multirow{5}{*}{$\begin{array}{l}\text { Saponins } \\
(\mathrm{mg} / \mathrm{l})\end{array}$} & C. sinensis(Sweet orange) & 0.030 & 0.030 & 0.000 \\
\hline & C. reticulata(Tangerine) & 0.050 & 0.070 & 0.000 \\
\hline & C. limonum(Lemon) & 0.055 & 0.045 & 0.000 \\
\hline & C.aurantifolia(Lime) & 0.050 & 0.055 & 0.000 \\
\hline & C.vitis(Grape fruits) & 0.050 & 0.050 & 0.000 \\
\hline Phenolics & C. sinensis(Sweet orange) & 0.350 & 0.435 & 0.049 \\
\hline
\end{tabular}

The analysis of extracts from peels, pulp and seeds of the citrus fruits showed presence of phenolics in the peel extracts of all citrus fruit species, in pulp extracts of $C$. reticulata, $C$. aurantifolia and $C$. vitis, and in seed extracts of $C$. sinensis, C. limonum, $C$. aurantifolia and $C$. vitis. Phenolics were absent in the pulp extracts of $C$. sinensis and $C$. limonum, and seed extract of $C$. reticulata only.

In the quantitative analysis of the extracts from peels, pulps and seeds, high levels or amounts of alkaloids were observed only in the seeds of $C$. sinensis; peels and pulp of $C$. reticulata; peels, pulp and seeds of $C$. limonum; pulp of $C$. aurantifolia; peels and seeds of $C$. vitis.

Similarly, high titres of flavonoids were observed in peels and pulp of $C$. sinensis; peels and seeds of $C$. reticulata; peels and seeds of $C$. limonum; peels and pulp of $C$. aurantifolia and peels and pulp of $C$. vitis. The peels, pulp and seeds of the five species of citrus fruits all showed high amount of Saponins in their extracts.

The phenolics showed very high levels or quantities in the extracts from the peels and pulps of $C$. sinensis, $C$. reticulata and $C$. vitis; pulp of $C$. limonumand $C$. aurantifolia. There were moderate amounts of phenolics in the seeds of $C$. sinensis, $C$. reticulata; peels and seeds of $C$. limonum, $C$ aurantifolia and seeds of $C$ vitis.

The quantitative analysis of the chemical compounds (i.e active ingredients) present in the different volatile oil extracts gave the values recorded in Table 2 . 


\begin{tabular}{|c|c|c|c|c|}
\hline \multirow[t]{4}{*}{$(\mathrm{mg} / \mathrm{l})$} & C. reticulata(Tangerine) & 0.330 & 0.351 & 0.072 \\
\hline & C. limonum(Lemon) & 0.046 & 0.229 & 0.061 \\
\hline & C.aurantifolia(Lime) & 0.078 & 0.361 & 0.036 \\
\hline & C.vitis(Grape fruits) & 0.240 & 0.351 & 0.033 \\
\hline \multirow{5}{*}{$\begin{array}{l}\text { Tannins } \\
(\mathrm{mg} / \mathrm{l})\end{array}$} & C. sinensis(Sweet orange) & 0.65 & 0.045 & 0.100 \\
\hline & C. reticulata(Tangerine) & 0.49 & 0.160 & 0.000 \\
\hline & C. limonum(Lemon) & 1.21 & 0.400 & 0.020 \\
\hline & C.aurantifolia(Lime) & 1.30 & 0.015 & 0.005 \\
\hline & C.vitis(Grape fruits) & 0.75 & 0.010 & 0.005 \\
\hline
\end{tabular}

Key: Values of active ingredients were measured in milligrams per litre.

\section{DISCUSSION}

This study has indeed established some very interesting facts about the relative efficacies of the different concentrations of phytochemical extracts from peels, pulp and seeds of the citrus fruit species on indoor resting adult mosquitoes in human living rooms. The $5 \%$ concentrations of all the extracts proved ineffective, and did not therefore kill any mosquito in all the rooms that were sprayed with it during both the initial and repeat sprays. This may mean that the $5 \%$ concentration was probably too low and weak to be able to produce lethal effect on mosquitoes in agreement with reports of Effiomet al., (12) and Effiomet al., (32) in which similar results were obtained. All others concentrations of the extracts produced reasonable mosquito death in the respective rooms they were sprayed. Mosquito death in relation to the different concentrations of the volatile oil extracts sprayed in the various rooms showed that mosquito lethality increased with corresponding increase in concentrations of the extracts sprayed in the rooms. A correlation test to establish the relationship between the numbers of mosquitoes killed and the different concentrations revealed a significant correlationship ( $\mathrm{P}>$ 0.01). It implies therefore that the numbers of dead mosquitoes increased with corresponding increase in concentrations of the extracts sprayed in the rooms. A similar test to verify the relationship between the species of citrus fruits and the corresponding numbers and genera of mosquitoes killed by their extract concentrations proved that the three parameters are significantly correlated $(\mathrm{P}>0.01)$. The same seed extracts were effective in killing mosquitoes just like peel extracts and in this case recorded average of 107 dead mosquitoes for C. aurantifolia, 109 for C. limonum, 84 for $C$. reticulataand 50 for $C$. vitis. It was only in $C$. sinensisthat extracts from pulp proved more active or potent than those from seeds, and accordingly recorded average numbers of 90 mosquitoes. In all the species of citrus fruits, only extracts from pulp proved less effective and recorded very low mosquito death in the rooms they were sprayed even at high concentration of $25 \%$ (Figures 1a - 1e). Another Pearson correlation test run between the average numbers of the different types of mosquitoes killed and the extracts from the different parts (peels, pulp and seeds) of the same species of the citrus fruits showed significant correlationship. The reason for this observation could be due the corresponding disparity in their active ingredients content, a finding which has collaborated the report of an earlier study by Okwu and Morah (26),Effiomet al., $(31,32)$ that the amount of these active compounds in citrus fruits differ from species to species. Indeed this was confirmed by the distribution of these compounds, phenolics, saponins, flavonoids, alkaloids, etc., in the citrus phytochemical extracts (Table 2). Also in line with the earlier observation of Okwu and Morah(6), Effiomet al., $(31,32)$, alkaloids were more abundant in the extracts from $C$. sinensis(Table 2) than in extracts from other citrus species, and therefore the high insecticidal activity of C. sinensis observed in this study could be attributed to the proportionate high amount of alkaloids, especially as alkaloids are said to have excellent potency against transmitters of disease agents. Statistically, there was significant correlation between alkaloids content and the potency of extracts obtained from C. reticulata, C. limonum, C. aurantifolia and $C$. vitis, with coefficient values of 0.082 , 0.024, 0.731 and 0.381, respectively, $(\mathrm{P}>0.01)$. Besides, Okwu and Morah, (26),Okwu and Emenike, (7), Effiomet al ., (31, 32), had earlier suggested that the biological implication of the presence of these active ingredients (alkaloids, flavonoids, saponin, phenolics and tannins), which by nature are endowed with antioxidants, plant protective toxins, medicaments and other anti-disease substances, may be the conferment of pesticidal/insecticidal, antifungal and antibacterial activity on the plant products. Generally, high number of Anophelines died compared to the Culicines(i.e., Culex and Aedes) probably because Culicine mosquitoes naturally are more adapted to polluted environment than the Anophelines, and that may be the reason why the Culicines can breed more successfully in polluted water bodies. Anophelines do not have tolerance capacity for environmental pollutants. It may also be that the rooms sprayed were more infested with indoor resting adult Anopheles mosquitoes (gambiae and funestus than the Culex and Aedes). On the other hand, however, the findings of this field demonstration study of the activity of citrus fruit extracts on indoor resting adult mosquitoes has disproved the earlier report of Herrera and Vieta (20), that citrus botanicals exhibit synergistic effect only when in combination with conventional botanical insecticides such as pyrethrum, and that their efficiency too is only enhanced by the use of a synergist such as technical piperonylbutoxide.

Apart from mosquitoes, a few other insects, precisely, houseflies and cockroaches were found dead in the rooms that were sprayed with high concentrations of the extracts. These dead houseflies and cockroaches were suspected to be killed by the citrus volatile oils that were sprayed in the rooms. It implies that citrus fruit-derived phytochemicals are not mosquito specific, hence ecotoxic.

Although the mode of action of the lethal effect of these citrus 
phytochemical extracts may be quite inexplicable, the suggestions of Matsumura, (3) and Bloomquist, (22) Effiomet al., (31) may also apply here. In their respective reports, these scholars suggested the lethal activity of phytochemicals on adult mosquitoes to be due to contact activity, stomach toxicity, respiratory toxicity or suffocation via spiracular or tracheal openings and neurotransmitter on the insect's central nervous system (CNS), as the active compounds enter the respiratory openings $(22,3,32)$.

\section{CONCLUSION}

The field demonstration of the efficacy of the volatile phytochemicals extracts from peels, pulp and seeds of the $C$. sinensis, $C$. reticulata, $C$. limonum, $C$. aurantifolia and $C$. vitis on the indoor resting adult mosquitoes have indeed exhibited mosquitocidal activity against mosquitoes under field conditions. Even though extracts from some of the citrus species proved effective only at very high concentrations, they all have good promise for adoption in sustainable malaria vector control programme.

Secondly, the death of houseflies and cockroaches in rooms sprayed with $20 \%$ and $25 \%$ concentration of the extracts implies that these products can equally be adopted as pesticides in insect pest control.

\section{RECOMMENDATION}

Having proved effective even under field conditions, it means that the prospects of using citrus fruit extracts in developing natural mosquitocides are eminent, and therefore recommendable. This is more so because, the raw materials for the production of these active mosquitocides are cheap, readily available, and the products themselves are environmentally safe, less risky to handle, less hazardous to non-insects, plants and animals. There is every need to promote the use of phytochemicals from citrus plants in community based sustainable vector control programmes.

\section{ACKNOWLDGEMENT}

We wish to very sincerely appreciate some persons for their immense contributions towards the successful accomplishment of this noble study. Prominent among them are all the team members for this study, and staff of the Biological Sciences Laboratory, Cross River University of Technology, Calabar, and Mr. Emmanuel O. Effiom (the Chief Technologist), of the Analytical Laboratory of the Department of Pure and Applied Chemistry, University of Calabar, Calabar, Cross River State, Nigeria, for providing the logistics for processing the citrus materials and for phytochemical extraction. Also to be appreciated are the Chiefs, Elders and Leaders of Thought of Abini community for their very wonderful understanding and cooperation during the study.

Use

\section{REFERENCES}

[1] G Koskinen, J. Citrus pages. Updated $19^{\text {th }}$ March, 2008. citruspages@suomi24.fi.

[2] Mathivanan, T., Govindarajan, M., Elumalai, K., Krishnappa, K and Ananthan, A Mosquito larvicidal and phytochemical properties of
ErvatamiacoronariaStapf. (Family: Apocynaceae). Journal of Vector Borne Diseases, 2010, 47:178-180.

[3] Matsumura, F.. Toxicity of insecticides (Second Edition). 1985, Plenum, New York.

[4] Morton, J. F..Fruits of warm climates. Creative Resource System Incorporated, Miami, Florida, 1987.

[5] Muturi, E. J., Burgess, P. and Navak, R. J.. Malaria Vector Management. Where have we come from and where are we headed? American Journal of Tropical Medicine and Hygiene, 2008, 78:536 537.

[6] Obadoni, B. O. and Ochuko, P. O. Phytochemical studies and comparative efficacy of the crude extracts of some homeostatic plants in Edo and Delta States of Nigeria. Global Journal of Pure and Applied Sciences, 2001,8:203-208.

[7] Okwu, D. E. and Emenike, I. N.. Evaluation of the phytonutrients and vitamins contents of citrus fruits. International Journal of Molecular Medicine and Advance Sciences, 2006, 2(1): 1 - 6.

[8] Bruce-Chwatt, L. J. Textbook of essential Malariology. London. William Heinemann Medical Book's limited, 1980.

[9] Cottin. Citrus of the World. A citrus directory. SRA-INRA-CIRAD. A catalogue of more than 5,500 citrus names classified by botanical, common and cultivar names. Comparison of Swingle and Tanaka terminology listing equivalent names of both United States, 2002.

[10] Green., M. M., singer, J. M., Sutherland, D. J. and Hibbon, C.R. Larval activity of Tagetesminuta(Marigold) towards Aedesaegypti.Journal of American Mosquito control Association, 1991, 7:282 - 286.

[11] Harborne., J. B. Phytochemical methods, a guide to modern techniques of plant Analysis. $3^{\text {rd }}$ Edition. Chapman and Hill Ltd., London, 1998, 279 pp.

[12] Rajmohan, D. and Ramaswamy, M.. Evaluation of Larvicidal activity of the leaf extract of a weed plant, Ageratinaadenophora, against two important species of mosquitoes, Aedesaegypti and Culexquinqufasciatus. African Journal of Biotechnology, 2007, 6 (5): 631-638.

[13] Redwane, A., Lazrek, H. B., Bouallam, S., Markouk, M., Amarouch, H. and Jana, M. Larvicidal activity of extracts from Querus Lusitania varinfectoria galls (oliv). Journal of Ethnopharmacology, 2002.,79:261-263.

[14] Service, M. W. A guide to medical entomology. London Macmillan Tropical and sub-Tropical Medical Text Press, 1980.

[15] Sukumar, K., Perich, M. J. and Boobar, L. R.. Botanical derivatives in mosquito control, a review. Journal of American Mosquito Control Association, 1991, 7: 210-237.

[16] Swingle, W. T. and Reece, P. C. The Botany of citrus and its wild relatives. In: Chapter 3 of the citrus industry, volume 1. United States, 1943.

[17] Van Burden T. P. and Robinson, W. C. Formation of complexes between protein and tannin acid. Journal of Agricultural Food Chemistry, 1981, 1:77.

[18] Wardowski, W. F., Nagy, S., Grierson, W. (Editors) Fresh Citrus Fruits. United Kingdom, 1986.

[19] World Health Organization (WHO). World Malaria Situation in 1960 Bulletin of World Health Organization, 1992a, 70. 801-807.

[20] Herrera, A, P and Vieto, S.A. Insecticidal use of orange juice essential oils. Panama. SPA, United States, 1980.

[21] Hodgson, R. W. Citrus Classification. In: Citrus Genetics, Breeding and Biotechnology. Editor: I. A. Khan. Biddles limited, Kings Lynn, UK, 1980.

[22] Bloomquist, J. R. Neuroreceptor mechanism in pyrethroid mode of action and resistance. Revelation of Pesticide Toxicity, 1993, 2. 185-226.

[23] Boham, A. B. and Kocipai, A. C. Flavonoids and condensed tannins from leaves of Hawaiian vaccininum reticulum and Vicalycinium. Pacific Science, 1994, 48:458-463.

[24] Indian Center for Malaria Research (ICMR). Prospects of using herbal products in the control of mosquito vectors. Bulletin, 2003, 33(1). 1-7.

[25] Khanna, V. and Kannabiran, K.Larvicidal effect of Hernidesmusindicus, Gymnemasylvestre, and Ecliptaprostrata against Culexquinquafasciatus mosquito larvae. African Journal of Biotechnology, 2007, 6 (3): 307-311.

[26] Okwu, D. E. and Morah, F. N. Antimicrobial and phytochemical evaluation of seed of Garcinia kola and Dennettiatripetala fruits. Journal of Medicinal and Aromatic Plants Sciences, 2007b, 29: 20 23.

[27] Okwu, D. E. Citrus fruits. a rich source of phytochemicals and their roles in human health. A review. International Journal of Chemical Sciences, 2008, 6(2). 451-471.

[28] Palsson, K. and Janeson, T. G. T. Plant products used as mosquito repellents in Guinea Bissu, West Africa, ActaTropica, 1999,72: 39-52. 
[29] Park, I. K., Lee S. G., Shin, S. C., Park, J. A. and Alm Y.J. Larvicidal activity of isobutylalanine identified in Piper nigrum fruit against three mosquito species. Journal of Agricultural Food Chemistry, 2002,50: 1866-1870.

[30] Prathibha, K. P., Raghavendra, B. S. and Vijayan, V. A. Evaluation of larvicidal effect of EuodiaridleyiHochr. Leaf extract against three mosquito species at Mysore. Research Journal of Biological Sciences, 2010, 5(6):452-455.

[31] Effiom, O. E. and Avoaja, D. A. Evaluation of Minimum Lethal Concentrations (MLCs) of Phytochemical Larvicide Extracts from Peels, Pulp and Seeds of five species of Citrus Fruits. World Journal of Applied Sciences and Technology, 2012, 4(1):13-19.

[32] Effiom, O. E., Avoaja, D. A., Ohaeri, C. C., Laboratory Assessment of the Bio-efficacies of the Phytochemical Extracts from Peels, Pulp and Seeds of Citrus species Against Anopheles gambiae and Anopheles funestus. Nigerian Journal of Parasitology, 2014, 34(1-2):71-81. 